\title{
Erratum to: Obstructive Sleep Apnea Screening and Airway Structure Characterization During Wakefulness Using Tracheal Breathing Sounds
}

\author{
Ahmed Elwali and Zahra Moussavi (i) \\ Biomedical Engineering Program, University of Manitoba, Winnipeg, MB, Canada
}

Erratum to: Annals of Biomedical Engineering (2016)

DOI: $10.1007 / \mathrm{s} 10439-016-1720-5$

This erratum is to correct the numbers presented in the last sentence of Section "B. Preprocessing". The sentence with corrected numbers is: "Out of the data in the two groups of OSA and non-OSA, we used a subset of randomly selected 105 subjects ( 50 non-OSA and 55 OSA) for investigating the characteristic features with most differences between the two groups."

Address correspondence to Zahra Moussavi, Biomedical Engineering Program, University of Manitoba, Winnipeg, MB, Canada. Electronic mail: Zahra.Moussavi@umanitoba.ca

The online version of the original article can be found under doi: 10.1007/s10439-016-1720-5. 